\title{
Differential Vulnerability of Outer and Inner Hair Cells during and after Oxygen-Glucose Deprivation in Organotypic Cultures of Newborn Rats
}

\author{
N. AMARJARGAL ${ }^{1}$, N. ANDREEVA ${ }^{2 *}$, J. GROSS ${ }^{1}$, H. HAUPT ${ }^{1}$, J. FUCHS ${ }^{1}$, \\ A. J. SZCZEPEK ${ }^{1}$, B. MAZUREK ${ }^{1}$ \\ ${ }^{1}$ Molecular Biology Research Laboratory, Department of Otorhinolaryngology, Charité - \\ Universitätsmedizin Berlin, Berlin, Germany, ${ }^{2}$ Brain Research Institute, Academy of Medical \\ Sciences, Moscow, Russia
}

Dr. Nadeshda Andreeva passed away in 2006. This paper is dedicated to her memory.

Received December 5, 2007

Accepted December 1, 2008

On-line December 17, 2008

\section{Summary}

Ischemia can contribute to the inner ear pathology and hearing loss. To determine the susceptibility of inner and outer hair cells (IHCs/OHCs) to ischemic and post-ischemic period, we used organotypic cultures of the organ of Corti isolated from $\mathrm{P} 3$ rats as an in vitro model of inner ear ischemia (oxygen-glucose deprivation, OGD). We identified the hair cells (HCs) by phalloidin staining. The cells with damaged cellular membrane integrity were identified by propidium iodide (PI)-exclusion assay. The cells with fragmented chromosomal DNA were detected by TUNEL assay. Organotypic cultures were subjected to a mild ( $3 \mathrm{~h}$ duration) or severe ( $4 \mathrm{~h}$ duration) OGD, followed by a recovery period of $21 \mathrm{~h}$ and $20 \mathrm{~h}$, respectively. Mild OGD induced a loss of $10-20 \% \mathrm{HCs}$, whereas severe OGD induced loss of $35 \% \mathrm{HCs}$. We confirmed that OHCs are less vulnerable to OGD than IHCs. Of all missing OHCs, 80-90\% was lost during the OGD period and $10-20 \%$ during the recovery period. In contrast, the loss of IHCs was equal during both experimental periods. The OGD period was mainly associated with PI-positive nuclei. TUNELpositive nuclei were a minor fraction during the OGD period and increased during the recovery period, indicating the progression of DNA fragmentation. Our results implicate a differential susceptibility of IHCs and OHCs during and after ischemia-like insult, which may be of therapeutic consequence.

\section{Key words}

Hair cell $\bullet$ Ischemia $\bullet$ Propidium iodide $\bullet$ TUNEL $\bullet$ Rat

\section{Corresponding author}

B. Mazurek, Molecular Biology Research Laboratory, Department of Otorhinolaryngology, Charité - Universitätsmedizin Berlin, Campus Charité Mitte, Charitéplatz 1, 10117 Berlin, Germany. Fax: +49-30-450555 908. E-mail: birgit.mazurek@charite.de

\section{Introduction}

Hypoxia and/or ischemia play a significant role in inner ear pathology and may contribute to hearing disorders such as sudden hearing loss, noise-induced damage and presbyacusis. These hearing disorders are often associated with a loss of the hair cells (HCs) in the organ of Corti. Previous studies showed that acute hypoxia/ischemia contribute to $\mathrm{HC}$ death and hearing impairment (Billett et al. 1989, Kim et al. 1999, Tsuji et al. 2002, Koga et al. 2003).

A specific marker of $\mathrm{HC}$ death is depolymerization of filamentous actin (F-actin). Phalloidin, substance that specifically binds F-actin, depicts the cuticular plate and stereocilia only in the healthy, intact HCs. To date, it is not known if F-actin depolymerization correlates with the changes in cell permeability and the DNA fragmentation, classical features associated with cell death. Changes in membrane permeability are associated with disturbances in ion 
homeostasis and occur early in the ischemia-induced cell death. A standard method to determine cellular permeability is the propidium iodide (PI) exclusion assay. In that assay, PI is excluded from a living cell by an intact membrane, thus staining only damaged cells and their nuclei. DNA fragmentation is a result of the activation of several nucleases as part of a complex cascade involved in the apoptosis (Samejima and Earnshaw 2005). A standard method to detect the single-stranded DNA fragmentation is the TUNEL assay (Gavrieli et al. 1992).

In our previous study, using F-actin staining we compared the $\mathrm{HC}$ response to oxygen deprivation (hypoxia) and oxygen-glucose deprivation (OGD) and found that the HC loss after OGD was significantly higher than that after hypoxia and that the inner hair cells (IHCs) are more vulnerable to both conditions than the outer hair cells (OHCs). Moreover, we observed a clear region-dependent vulnerability to hypoxia/ischemia with the lowest HC loss in the apical and the highest HC loss in the basal cochlear segment (Mazurek et al. 2003).

The aim of present study was to analyze the differential vulnerability of IHCs and OHCs during OGD and after OGD of different duration. Additionally, we wanted to evaluate the time course of two damaging mechanisms: the membrane permeability changes and the DNA fragmentation, both initiated by OGD. We expected that in addition to identification of intact HCs by the F-actin staining, the sequential use of PI-exclusion assay and TUNEL assay will enable us to associate the HC loss with changes in membrane permeability and DNA fragmentation during and after the OGD periods.

\section{Methods}

\section{Organotypic culture conditions}

Wistar rat pups (postnatal day 3-5, $\mathrm{n}=44$ ) were purchased from Federal Institute for Risk Assessment, Berlin, Germany. The organs of Corti were prepared as described previously (Sobkowicz et al. 1993, Lowenheim et al. 1999, Mazurek et al. 2003). We tried to dissect the organ of Corti away from the edge of the spiral ganglion between the limbus and the spiral ganglion throughout the cochlear spiral. Thus, most of the spiral ganglion cell body remained with the modiolus. As previously reported, the loss of innervation has no effect on $\mathrm{HC}$ survival (Sobkowicz et al. 1999).

The explants were cultured in 4-well microtiter plates (Nunc, Roskilde, Denmark) in the neurobasal medium with N1 supplement (Gibco Invitrogen
Corporation, Auckland, New Zealand) and $100 \mathrm{U} / \mathrm{ml}$ penicillin (Sigma, Saint Louis, MO, USA). On day zero, the organs of Corti were prepared, dissected into apical, middle and basal segments and transferred separately to the medium. The reason for separating the cochlea into three parts was their different vulnerability to ischemia as shown earlier (Mazurek et al. 2003). On day one, to mimic ischemic and control conditions, the medium was replaced with an artificial perilymph (APL) with and without glucose (Edge et al. 1998). Control explants were cultured under normoxic conditions in glucosesupplemented APL, whereas experimental explants were exposed to hypoxia in glucose-free APL in a Billups chamber (Del Mar, CA, USA) perfused with a calibrated gas mixture of $5 \% \mathrm{CO}_{2}$ and $95 \% \mathrm{~N}_{2}$ (AGA Gas GmbH, Bottrop, Germany) as described earlier (Mazurek et al. 2003). Explants were collected either immediately after the OGD period or $24 \mathrm{~h}$ after onset of OGD.

The cultures were grouped as follows: (1) controls incubated in APL for $3 \mathrm{~h}$ or $4 \mathrm{~h}$ and examined immediately thereafter $(n=11$ organs of Corti) or returned to the culture-conditioned medium and maintained for subsequent $21 \mathrm{~h}$ or $20 \mathrm{~h}$, respectively $(\mathrm{n}=17)$; (2) cultures exposed to moderate $(3 \mathrm{~h})$ or severe ( $4 \mathrm{~h})$ OGD and examined immediately after the end of OGD period ( $\mathrm{n}=10$ each); (3) cultures exposed to the same OGD periods as in (2) and maintained for the subsequent $21 \mathrm{~h}$ or $20 \mathrm{~h}$ recovery period in a cultureconditioned medium in a humidified incubator at $37{ }^{\circ} \mathrm{C}$ and $5 \% \mathrm{CO}_{2}(3 \mathrm{~h}, \mathrm{n}=18 ; 4 \mathrm{~h}, \mathrm{n}=22)$.

We have chosen to expose the organotypic cultures to $3 \mathrm{~h}$ or $4 \mathrm{~h}$ of OGD because these times reflect mild and severe ischemia-like conditions, respectively (Mazurek et al. 2003).

All studies were approved by the State Office of Health and Social Affairs (LaGeSo), Berlin, Germany (T0234/00).

\section{Specimen staining and scoring protocols}

Three techniques were used in a strictly specific order to identify HCs or nuclei. First, after indicated time of OGD, propidium iodide (PI, $1 \mu \mathrm{g} / \mathrm{ml}$; Molecular Probes, Eugene, OR, USA) was added for 8-10 min to the explants in culture. PI is a DNA intercalating fluorescent probe. Under these specific conditions, it is used to visualize the nuclei of cells with a damaged, permeable plasma membrane. The number of cells with PI-positive nuclei (red) was counted along the $100-\mu \mathrm{m}$ sections in each segment of the organ of Corti using epifluorescent 


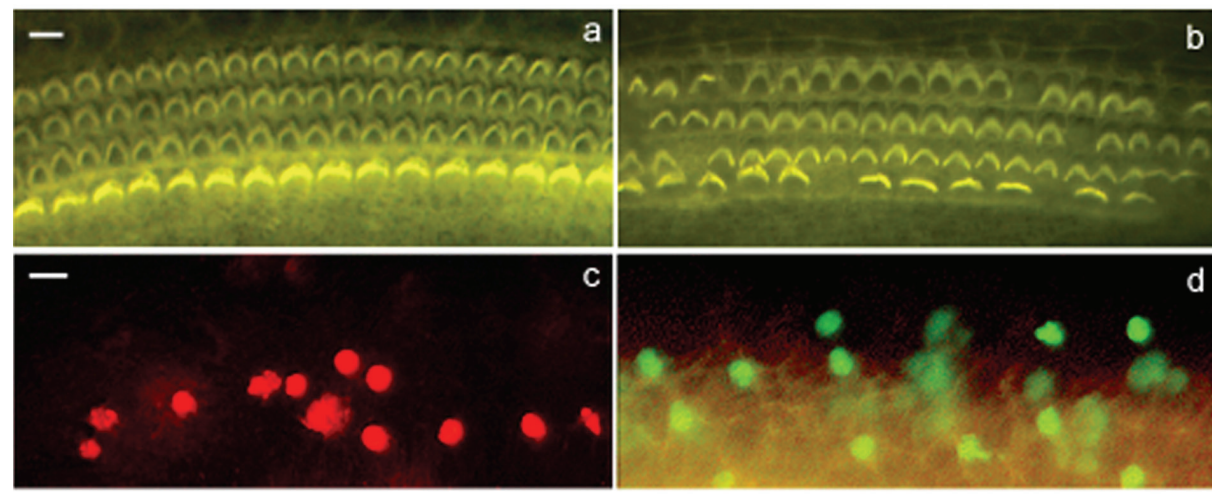

Fig. 1 a-d. Typical images of the rat organ of Corti explants after $48 \mathrm{~h}$ in vitro culture. Phalloidin-TRITC staining of control shows three welldefined rows of outer hair cells and one row of inner hair cells in the control explants (a) and missing hair cells in OGD-exposed explants (b). Panel c shows the fluorescent image of PI-positive nuclei indicating damaged cell membranes (red). Panel $\mathbf{d}$ shows the fluorescent image of TUNEL-positive nuclei (green) which were counted simultaneously with the phalloidin-stained hair cells (red). Bar $=10 \mu \mathrm{m}$.

microscopy. Second, the explants were washed twice with glucose solution in a buffered saline, fixed in $4 \%$ paraformaldehyde in isotonic phosphate-buffered solution, permeabilized with $0.2 \%$ Triton solution in PBS and stained using tetramethyl rhodamine isothiocyanate (TRITC)-labeled phalloidin (Sigma, Saint Louis, MO, USA). Last, nuclear DNA fragmentation was detected using TUNEL-based ApopTag Plus Fluorescein In Situ Apoptosis Detection Kit (Intergen company, Purchase, NY, USA) according to the manufacturer's recommendation.

The phalloidin-labeled (orange) $\mathrm{HCs}$ were counted in all three $\mathrm{OHC}$ rows and in the IHC row. HCs were considered missing when there was a gap in the normal geometric array where no stereocilia or cuticular plates were seen. The TUNEL-positive (green) nuclei were successively counted in the same cochlear segments. Leica fluorescent DMIL microscope was used for all evaluations (magnification x 400). Microphotographs were taken by a Canon PowerShot S40 digital camera mounted on the Leica fluorescent microscope. Images were imported into Adobe Photoshop 9.0, where standard methods were used to optimize contrast and brightness.

We examined at least three $100-\mu \mathrm{m}$ sections in each segment of the organ of Corti. To eliminate falsepositive cells, where death was induced during explant preparation, about $50-\mu \mathrm{m}$ sections at both ends of the segments were excluded from the examination.

\section{Statistical analyses}

Means \pm S.E.M. were calculated for all parameters measured. The statistical processing of the results was performed using two-way ANOVA followed by contrast analysis to compare individual means. $\mathrm{P}<0.05$ was the criterion of significance. All statistical tests and graphics were made using Statistica 7.1 (StatSoft).

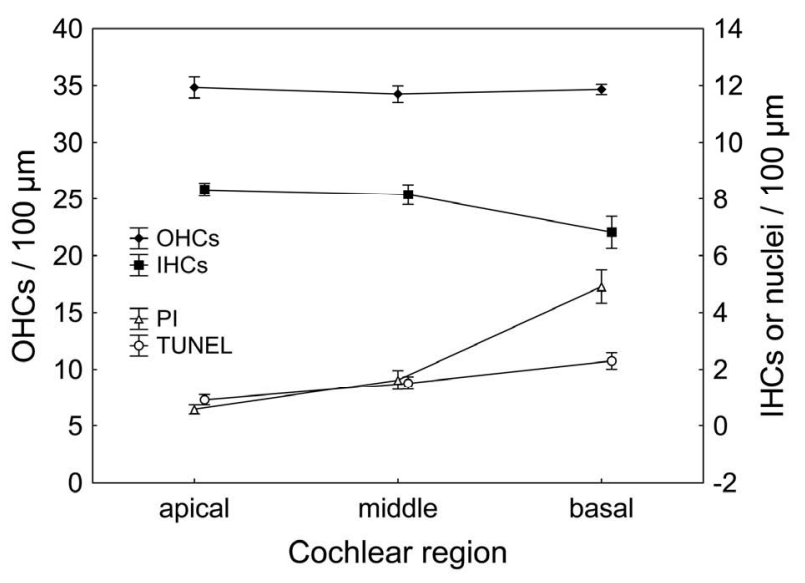

Fig. 2. Numbers of outer and inner hair cells (OHCs/IHCs) and PI- and TUNEL-positive nuclei in the apical, middle and basal segments of the control cultures (mean \pm S.E.M.). The numbers of OHCs (left y-axis) or IHCs, PI- and TUNEL-positive nuclei (right $\mathrm{y}$-axis) are given as $\mathrm{n}$ per $100 \mu \mathrm{m}$ length of the organ of Corti. Because there were no significant differences between the control explants cultured for either $3 \mathrm{~h}$ or $4 \mathrm{~h}$ under normoxic conditions, the values were combined.

\section{Results}

\section{Control cultures}

We have identified HCs and their nuclei using cytological and cytochemical methods in sequential steps (Fig. 1). Figs 1a and $1 \mathrm{~b}$ demonstrate F-actin staining of HCs with phalloidin-TRITC. Organ of Corti cultured under control normoxic conditions displays regular architecture (Fig. 1a), whereas organ of Corti cultured under OGD conditions has visible gaps in the F-actin positive cell rows (Fig. 1b). Fig. 1c demonstrates a typical picture obtained as a result of vital test PIexclusion assay after OGD. Only the nuclei of cells with damaged membranes are labeled red. Fig. 1d shows a typical outcome of TUNEL assay in the organ of Corti after ischemia. Green color indicated presence of singlestranded DNA brakes in the nuclei of damaged, apoptotic 

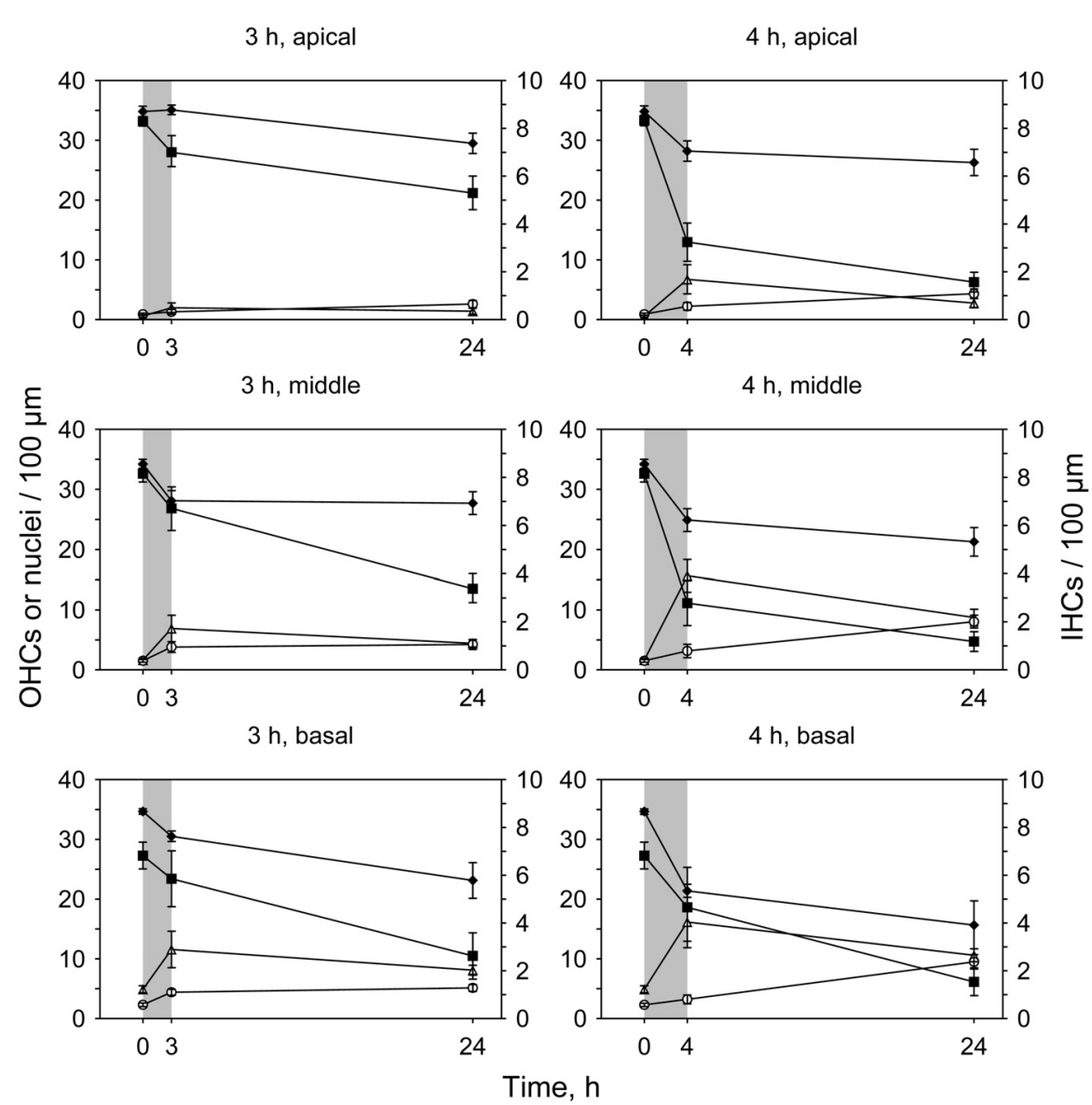

Fig. 3. Numbers of outer and inner hair cells (OHCs/IHCs) and PI- and TUNELpositive nuclei in the apical, middle and basal segments before and after $3 \mathrm{~h}$ or $4 \mathrm{~h}$ of OGD and at the end of the recovery periods. Plotted are the mean numbers ( \pm S.E.M.) of OHCs, PI- and TUNEL-positive nuclei (left $y$-axis) or IHCs (right $y$-axis) per $100 \mu$ m length of the organ of Corti. Shadow indicates the exposure to OGD (closed diamonds, OHCs; closed squares, IHCs; open triangles, PI-stained nuclei; open circles, TUNEL-stained nuclei). cells. In the basal, middle and apical segments of the control cultures, we scored 34.3-34.8 OHCs (3 rows) and 6.8-8.3 IHCs (1 row) per $100 \mu \mathrm{m}$ length of the organ of Corti (Fig. 2). We also observed a few cells, with a PI-positive (0.6-4.9) or ApopTag-positive (0.9-2.3) positive nuclei per $100 \mu \mathrm{m}$. These cells most likely represented spontaneous $\mathrm{HC}$ loss in the normoxic culture, mainly in the basal part of tissue.

Changes in the HC loss and in the numbers of PI- and TUNEL-positive nuclei during and after the OGD periods

Here, we wanted to know if there are differences in the dynamics of cell loss during and after OGD. First, we compared the numbers of intact OHCs, IHCs and of the PI- and TUNEL-positive nuclei before and after OGD and after the recovery period (Fig. 3 ). The mild ( $3 \mathrm{~h}$ ) and the severe $(4 \mathrm{~h})$ OGD induced a decrease in the numbers of IHCs and OHCs during the OGD period as well as after recovery periods. The numbers of the PI-positive nuclei increased rapidly during the OGD period and decreased slowly during the recovery period. In contrast, the numbers of the TUNEL-positive nuclei increased continuously during and after the OGD period.
Loss of IHCs and OHCs during and after the OGD periods

To analyze the differences in the dynamics of the IHC and OHC loss during and after the OGD periods, we represented the values as a percentage of the controls. Interestingly, we observed a difference in pattern of cell loss between the OHCs and IHCs (Fig. 4). Three hours of OGD induced an overall loss of 10-15\% of OHCs and IHCs. During the recovery period, OHC loss increased by further $10 \%$, whereas IHC loss increased by further $40 \%$ $(\mathrm{p}<0.05$ and $\mathrm{p}<0.001$ vs. immediately after OGD). Following $4 \mathrm{~h}$ of OGD, the mean OHC loss was in the range of $30 \%$ and the mean IHC loss was in the range of $50 \%$. During the recovery period, no further loss was observed for OHCs (n.s.), but there was an additional $30 \%$ loss for IHCs ( $\mathrm{p}<0.001$ vs. immediately).

\section{Changes of PI-exclusion and DNA fragmentation during and after the OGD periods}

The number of cells with PI- or TUNEL-positive nuclei showed remarkable differences between the OGD and recovery periods (Fig. 5). After moderate OGD (3 h), between 2-12 PI-positive nuclei per $100 \mu \mathrm{m}$ lengths of the organ of Corti were counted showing a clear apical- 


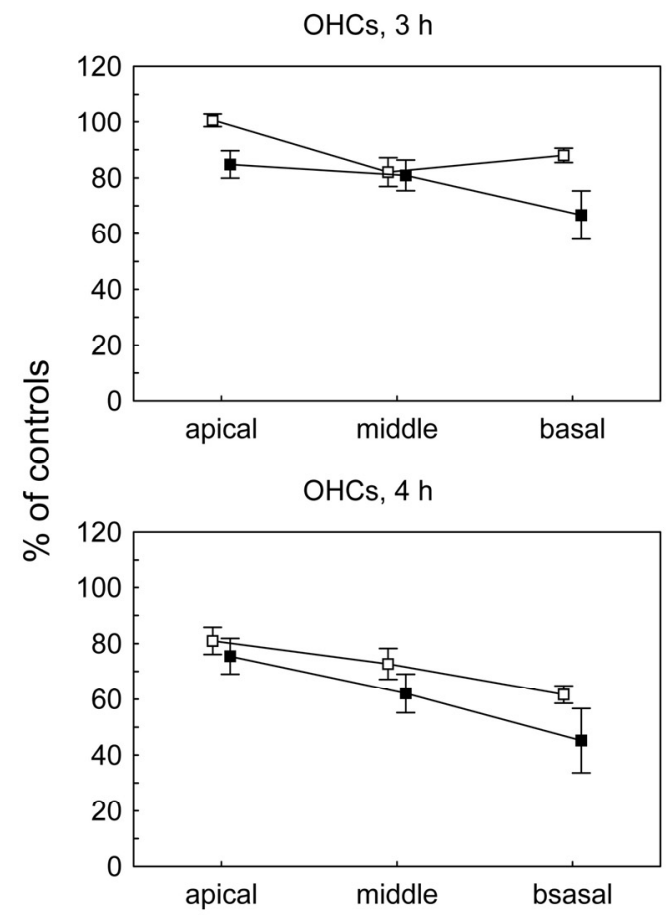

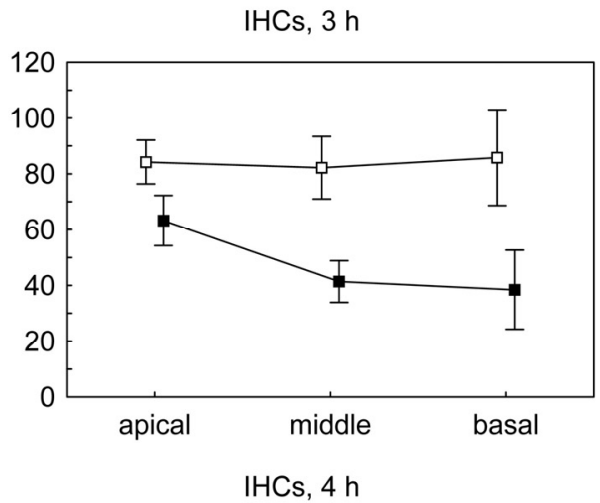

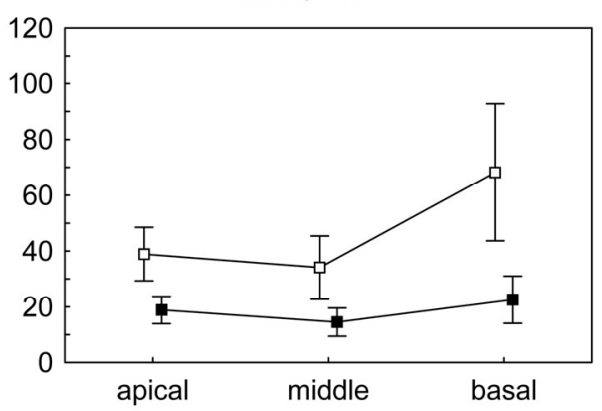

Fig. 4. Percentage (mean \pm S.E.M.) of outer and inner hair cells $(\mathrm{OHCs} / \mathrm{IHCs})$ in the apical, middle and basal segments immediately after ending the OGD (open squares) and recovery (closed squares) periods. Top: $3 \mathrm{~h}$ OGD and $21 \mathrm{~h}$ recovery period; bottom: $4 \mathrm{~h}$ OGD and $20 \mathrm{~h}$ recovery period. The mean number of hair cells of corresponding regions from the normoxic cultures was used as $100 \%$. basal gradient $(\mathrm{p}<0.01)$. Unexpectedly, the PI-numbers decreased during the recovery period to 1-8 stained nuclei ( $p<0.05$ vs. immediately). After severe OGD (4 h), 7-16 PI-positive nuclei per $100 \mu \mathrm{m}$ were counted. Surprisingly, only 3-11 PI-positive nuclei were counted in the recovery period ( $p<0.001$ vs. immediately). The number of nuclei detected by ApopTag was in general lower (about $50 \%$ ) than the number of PI-positive nuclei. However, there was also an apical-basal gradient in the number of TUNEL-positive nuclei $(\mathrm{p}<0.01)$. In contrast to the PI-positive nuclei, the numbers of TUNEL-positive nuclei did not change during the recovery period following moderate OGD ( $3 \mathrm{~h})$, but they increased after severe OGD ( $4 \mathrm{~h})(\mathrm{p}<0.001$ vs. immediately).

\section{Discussion}

The aim of the present study was to analyze the $\mathrm{HC}$ loss during and after OGD periods and to compare it with the changes in the membrane permeability and the DNA fragmentation, both indicative of an ongoing cell death process. The loss of OHCs and IHCs occurred during and after the OGD periods; however, we observed remarkable differences between OHCs and IHCs. First, IHCs were generally more vulnerable to OGD than OHCs. OHCs were mainly lost during the OGD period, whereas the IHCs were lost during and after the OGD periods to an equal degree. Second, during OGD period, the number of cells with damaged plasma membranes (PI- positive nuclei) rapidly increased. At the same time, the number of cells with single-stranded chromosomal DNA breaks (TUNEL-positive) was relatively low. During the recovery period, the number of cells with damaged plasma membranes decreased and the number of cells with damaged chromosomal DNA progressed continuously.

\section{Loss of IHCs and OHCs}

We identified HC death by a lack of phalloidin staining, indicative of F-actin depolymerization. F-actin is the major component of the structural filaments in the HCs and is localized primarily in the cuticular plate and stereocilia of the HCs. The disassembly of actin is believed to be a result of proteolytic cleavage by proteases and caspases ( $\mathrm{Hu}$ et al. 2002). Actin cleavage and disruption of actin organization is an important factor in ischemic cell injury (Schwartz et al. 1999, Shelden et al. 2002) and has been associated with ATP depletion (Shelden et al. 2002). Phalloidin staining is regarded as the gold standard in determination of the anatomical presence of HCs. Our data confirm previous in vitro and in vivo studies, which showed that IHCs are more vulnerable to ischemia than OHCs (Taniguchi et al. 2002, Mazurek et al. 2003) and that ischemia-induced HC death rates show an apical-basal gradient (Billett et al. 1989, Koga et al. 2003, Mazurek et al. 2003). Our new finding is that OHCs die mainly during OGD, whereas IHC death occurs during and after OGD periods. Thus, the time course of IHC loss shows similarities to the delayed 


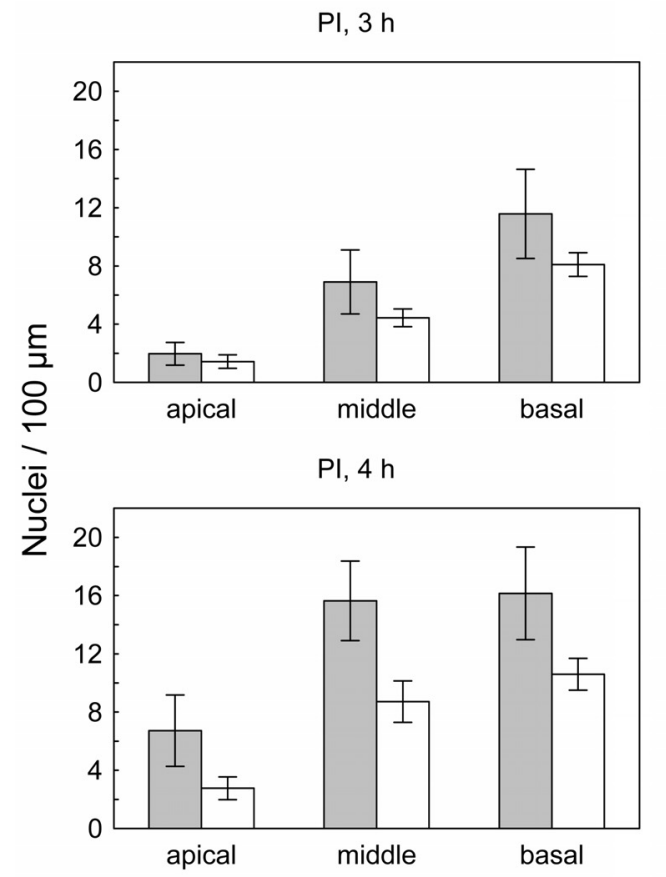

TUNEL, $3 \mathrm{~h}$
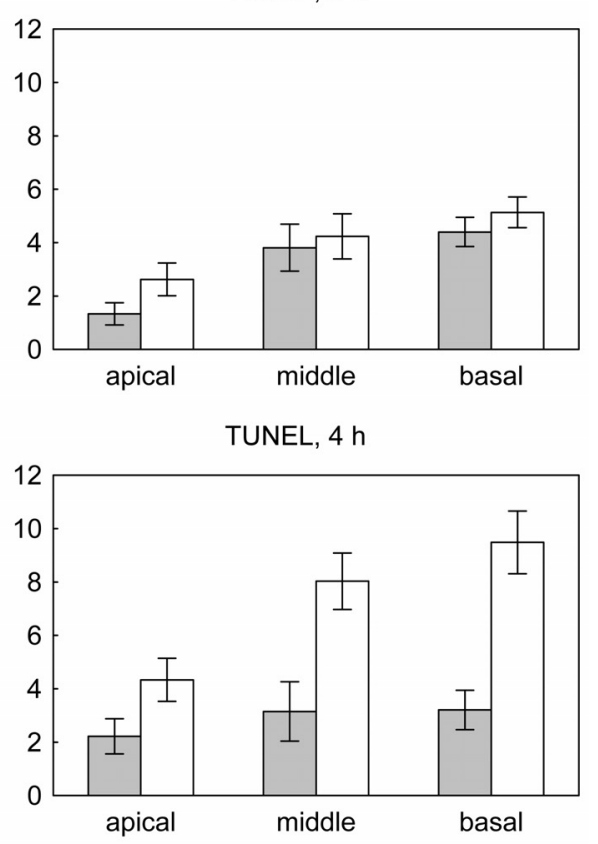

Fig. 5. Numbers of PI- and TUNEL-positive nuclei counted in the apical, middle and basal segments immediately after ending the OGD (grey bars) and recovery (white bars) period. Top: $3 \mathrm{~h}$ OGD and $21 \mathrm{~h}$ recovery period; bottom: $4 \mathrm{~h}$ OGD and $20 \mathrm{~h}$ recovery period. Given are the nuclei numbers per $100 \mu \mathrm{m}$ organ of Corti (mean \pm S.E.M.). neuronal death observed in the brain. Our in vitro findings are in agreement with the observations by Koga et al. (2003) who used an in vivo ischemia model confirming physiological validity of using explant cultures for this type of experiments.

There are some important metabolic and molecular differences between IHCs and OHCs, which may underlie their differential vulnerability during the ischemic and post-ischemic periods. The key factor for ischemia-induced cell death is the decrease of ATP level triggering several degrading systems, for example ion flow deregulation resulting in cell swelling, membrane injury, calcium overload and the introduction of mitochondrial permeability transition (Lipton 1999). The overall higher vulnerability of IHCs to ischemia as compared to OHCs may have its origin in the following metabolic and molecular differences between these two cell types: (i) IHCs express a smaller amount of the intracellular calcium ATPase (Schulte 1993); (ii) IHCs and OHCs have a different expression pattern of the plasma membrane calcium ATPase (PMCA), which transports calcium out of the cells and is responsible for normalization of the cytosolic calcium after ischemia (Lehotsky et al. 2002); (iii) in contrast to OHCs, IHCs have glutamate receptors, which are the molecular basis of the so-called excitotoxicity (Pujol et al. 1990). Above features may possibly account for a delayed IHC death. Our findings may be of clinical significance, implying that a proper time for intervention in order to protect OHCs should be during an ischemic insult, whereas for IHCs, intervention in post- ischemic period may still be useful.

\section{Cell permeability}

In our present study, we used PI as a vital dye marking nuclei of cells with disrupted cell membrane. PI is a DNA intercalating fluorescent probe that diffuses into cells as a result of plasma membrane damage. Viable or apoptotic cells exclude dyes such as PI or trypan blue (Darzynkiewicz et al. 1992). Our data show that the increase in cell permeability is a process dominating during the OGD period. Remarkably, during the recovery period, the number of PI-positive nuclei decreases, most probably because of the elimination of these cells over time (Fig. 3). Another interpretation of the change in PI-positive nuclei numbers is the recovery of membrane non-permeability during the recovery period, documented earlier in other types of cells (Chen et al. 2001). However, the continuous decrease of HC numbers during and after OGD periods clearly indicates that no recovery of HCs with PI-stained nuclei occurred. Our data suggest that the membrane permeability increases rapidly during OGD, implying damage or loss of function in the transmembrane ionic pumps. It is tempting to speculate that pharmacological prevention of membrane permeability could protect the OHCs from death during ischemia.

\section{DNA fragmentation}

We used the TUNEL assay as an indicator of nuclear DNA fragmentation, which is a typical feature of apoptosis (Gavrieli et al. 1992, Migheli et al. 1995). In 
general, apoptotic cells preserve most functions of the membrane (Darzynkiewicz et al. 1992). There is a close correlation between the morphological features of apoptosis, TUNEL staining and DNA laddering (Maulik et al. 1998, Das et al. 2005). The number of TUNELpositive nuclei is lower during the OGD period and increases progressively during the recovery period. The progression of TUNEL positivity together with an increase in F-actin-negative cell number during the recovery period indicates a preference for apoptotic cell death during that time.

\section{Limitations of the organotypic culture}

We are aware that the data obtained from explants isolated from young rat pups before the onset of hearing needs to be carefully interpreted. For example, mature neurons show an increased sensitivity to excitotoxicity and ischemia (Schuchmann et al. 2005). However, it is interesting to note that the main findings of the present study are in agreement with those obtained in other experimental in vitro and in vivo ischemia models where adult animals were used. A higher death rate of IHCs vs. OHCs and a clear apical-basal gradient in $\mathrm{HC}$ vulnerability were observed also in vivo (Koga et al. 2003). It seems that fundamental processes like cell survival or death have features, which are similar in vivo and in vitro in immature and mature animals (Zhu et al. 2005). The clear advantage of the culture model is the easy accessibility to the HCs and a simple and welldefined handling of the ischemic conditions.

\section{Conclusions}

Our data show that $80-90 \%$ of all OHC loss during presented experiments occurs during the OGD period. The increase in membrane permeability is a main pathophysiological process, which may likely contribute to the HC loss. Thus, we conclude that intervention during or immediately after an ischemic period would be an optimal approach to protect OHCs from cell death. In addition, new therapy approaches targeting cell membrane lesions are necessary for effective treatment. For example, cytoskeletal-antigen specific immunoliposomes were successfully used to minimize cell membrane lesions in hypoxic cardiocytes (Khaw et al. 2007) and to prevent cell death by targeting cell membrane sealing.

In contrast, the loss of IHCs occurs to a comparable degree during the OGD and the recovery periods. It is important to note that the overall loss of IHCs is higher than that of OHCs. The main pathophysiological feature of the post-ischemic period seems to be the DNA fragmentation. Interruption of the DNA fragmentation (e.g. by local application of caspase blockers) may create a chance to protect some IHCs by therapeutic measures during the post-ischemic period. However, only a small portion of HCs may be protected after an ischemic event. The different death kinetics of OHCs and IHCs during and after OGD periods indicates that $\mathrm{HC}$ protection needs therapeutic approaches during or immediately after the damaging event.

The understanding of the contribution of the ischemic and post-ischemic periods to the $\mathrm{HC}$ loss and its association with fundamental cell damaging processes may help to improve prevention and therapy of the HC loss.

\section{Conflict of Interest}

There is no conflict of interest.

\section{Acknowledgements}

This work was supported by grants from the Humboldt University, Berlin (2003-415) and from the SonnenfeldFoundation, Berlin. Dr. Nadjeshda Andreeva was supported by the Russian Foundation for Basic Research and by the Humboldt University, Office for International Relations.

\section{References}

BILLETT TE, THORNE PR, GAVIN JB: The nature and progression of injury in the organ of Corti during ischemia. Hear Res 41: 189-197, 1989.

CHEN J, LIU X, MANDEL LJ, SCHNELLMANN RG: Progressive disruption of the plasma membrane during renal proximal tubule cellular injury. Toxicol Appl Pharmacol 171: 1-11, 2001.

DARZYNKIEWICZ Z, BRUNO S, DEL BINO G, GORCZYCA W, HOTZ MA, LASSOTA P, TRAGANOS F: Features of apoptotic cells measured by flow cytometry. Cytometry 13: 795-808, 1992.

DAS A, SRIBNICK EA, WINGRAVE JM, DEL RE AM, WOODWARD JJ, APPEL SH, BANIK NL, RAY SK: Calpain activation in apoptosis of ventral spinal cord 4.1 (VSC4.1) motoneurons exposed to glutamate: calpain inhibition provides functional neuroprotection. $J$ Neurosci Res 81: 551-562, 2005. 
EDGE RM, EVANS BN, PEARCE M, RICHTER CP, HU X, DALLOS P: Morphology of the unfixed cochlea. Hear Res 124: 1-16, 1998.

GAVRIELI Y, SHERMAN Y, BEN SASSON SA: Identification of programmed cell death in situ via specific labeling of nuclear DNA fragmentation. J Cell Biol 119: 493-501, 1992.

HU BH, HENDERSON D, NICOTERA TM: F-actin cleavage in apoptotic outer hair cells in chinchilla cochleas exposed to intense noise. Hear Res 172: 1-9, 2002.

KIM JS, LOPEZ I, DIPATRE PL, LIU F, ISHIYAMA A, BALOH RW: Internal auditory artery infarction: clinicopathologic correlation. Neurology 52: 40-44, 1999.

KOGA K, HAKUBA N, WATANABE F, SHUDOU M, NAKAGAWA T, GYO K: Transient cochlear ischemia causes delayed cell death in the organ of Corti: an experimental study in gerbils. J Comp Neurol 456: 105-111, 2003.

KHAW BA, DA SILVA J, HARTNER WC: Cytoskeletal-antigen specific immunoliposome-targeted in vivo preservation of myocardial viability. J Control Release 120: 35-40, 2007.

LIPTON P: Ischemic cell death in brain neurons. Physiol Rev 79: 1431-1568, 1999.

LEHOTSKY J, KAPLÁN P, MURIN R, RAEYMAEKERS L: The role of plasma membrane $\mathrm{Ca}^{2+}$ pumps (PMCAs) in pathologies of mammalian cells. Front Biosci 7: D53-D84, 2002.

LOWENHEIM H, KIL J, GULTIG K, ZENNER HP: Determination of hair cell degeneration and hair cell death in neomycin treated cultures of the neonatal rat cochlea. Hear Res 128: 16-26, 1999.

MAULIK N, YOSHIDA T, ENGELMAN RM, DEATON D, FLACK JE, III, ROUSOU JA, DAS DK: Ischemic preconditioning attenuates apoptotic cell death associated with ischemia/reperfusion. Mol Cell Biochem 186: 139$145,1998$.

MAZUREK B, WINTER E, FUCHS J, HAUPT H, GROSS J: Susceptibility of the hair cells of the newborn rat cochlea to hypoxia and ischemia. Hear Res 182: 2-8, 2003.

MIGHELI A, ATTANASIO A, SCHIFFER D: Ultrastructural detection of DNA strand breaks in apoptotic neural cells by in situ end-labelling techniques. $J$ Pathol 176: 27-35, 1995.

PUJOL R, REBILLARD G, PUEL JL, LENOIR M, EYBALIN M, RECASENS M: Glutamate neurotoxicity in the cochlea: a possible consequence of ischaemic or anoxic conditions occurring in ageing. Acta Otolaryngol Suppl 476: 32-36, 1990.

SAMEJIMA K, EARNSHAW WC: Trashing the genome: the role of nucleases during apoptosis. Nat Rev Mol Cell Biol 6: 677-688, 2005.

SCHUCHMANN S, BUCHHEIM K, HEINEMANN U, HOSTEN N, BUTTGEREIT F: Oxygen consumption and mitochondrial membrane potential indicate developmental adaptation in energy metabolism of rat cortical neurons. Eur J Neurosci 21: 2721-2732, 2005.

SCHULTE BA: Immunohistochemical localization of intracellular Ca-ATPase in outer hair cells, neurons and fibrocytes in the adult and developing inner ear. Hear Res 65: 262-273, 1993.

SCHWARTZ N, HOSFORD M, SANDOVAL RM, WAGNER MC, ATKINSON SJ, BAMBURG J, MOLITORIS BA: Ischemia activates actin depolymerizing factor: role in proximal tubule microvillar actin alterations. Am J Physiol 276: F544-F551, 1999.

SHELDEN EA, WEINBERG JM, SORENSON DR, EDWARDS CA, POLLOCK FM: Site-specific alteration of actin assembly visualized in living renal epithelial cells during ATP depletion. J Am Soc Nephrol 13: 2667-2680, 2002.

SOBKOWICZ HM, LOFTUS JM, SLAPNICK SM: Tissue culture of the organ of Corti. Acta Otolaryngol Suppl 502: 336, 1993.

SOBKOWICZ HM, SLAPNICK SM, AUGUST BK: Apoptosis of inner hair cells caused by laser ablation of their spiral ganglion neurons in cultures of the mouse organ of Corti. J Neurocytol 28: 939-954, 1999.

TANIGUCHI M, HAKUBA N, KOGA K, WATANABE F, HYODO J, GYO K: Apoptotic hair cell death after transient cochlear ischemia in gerbils. Neuroreport 13: 2459-2462, 2002.

TSUJI S, TABUCHI K, HARA A, KUSAKARI J: Long-term observations on the reversibility of cochlear dysfunction after transient ischemia. Hear Res 166: 72-81, 2002.

ZHU C, WANG X, XU F, BAHR BA, SHIBATA M, UCHIYAMA Y, HAGBERG H, BLOMGREN K: The influence of age on apoptotic and other mechanisms of cell death after cerebral hypoxia-ischemia. Cell Death Differ 12: 162$176,2005$. 